\title{
Labeling GM foods—-the ethical way forward
}

\author{
Michael Reiss
}

Those who make decisions and implement policy in the European Commission and the European Parliament are almost all well intentioned. However, since July 2001, a series of proposals have been rumbling that threaten to waste a great deal of money, alarm people unnecessarily, and delay the introduction of new biotechnological products. These consequences are now more likely than ever as a result of votes in the European Parliament on July 3, 2002.

I refer to the proposals from the European Commission on traceability and labeling of genetically modified organisms (GMOs) and food and feed products derived from them ${ }^{1}$. As is widely realized, the food-labeling proposals go beyond current standards by requiring labels for all foods produced by GMOs regardless of whether detectable DNA or proteins are in those products 2 . Several objections have been raised against these proposals on the grounds of practicality (the availability of the necessary analytical detection methods), fairness (the possibility of discrimination against certain producers and countries), and $\operatorname{cost}^{3}$.

However, here I want to go to the heart of the two usual arguments in favor of this labeling: first, that such labeling is ethical, and second, that people want it. The second issue is more easily dealt with. Of course, if you ask people, "Do you want labeling?" most will say yes, but it is facile and misleading to conclude from this that labeling is really what they want. People need to know the consequences of policies, including compulsory labeling, and they need to know the arguments for and against them. Various surveys (such as the Eurobarometer in Europe) do not offer relevant accompanying information to provide such preliminary education. You might as well ask people "Do you want lower taxes?" Most people will say yes. The real question is something like "Do you want lower taxes and an accompanying reduction

Michael Reiss is professor of science education at the University of London Institute of

Education. Until December 31, 2001 he was the ethicist on the UK Government's Advisory Committee on Novel Foods and Processes and Chair of EuropaBio's Advisory Group on Ethics. From 2001-2002 he was the specialist advisor to the House of Lords Select Committee on Animals in Scientific Procedures(m.reiss@ioe.ac.uk). in such public services as education, health, transport, law enforcement, and defense?"

The ethical issue is subtler than the one to do with what the public wants. At one point, I assumed-and argued in a book I wrote with Roger Straughan ${ }^{4}$ - that labeling was the way forward for GM foods on the grounds that labeling provides information, that information allows choice, and that choice is a good thing. However, I have

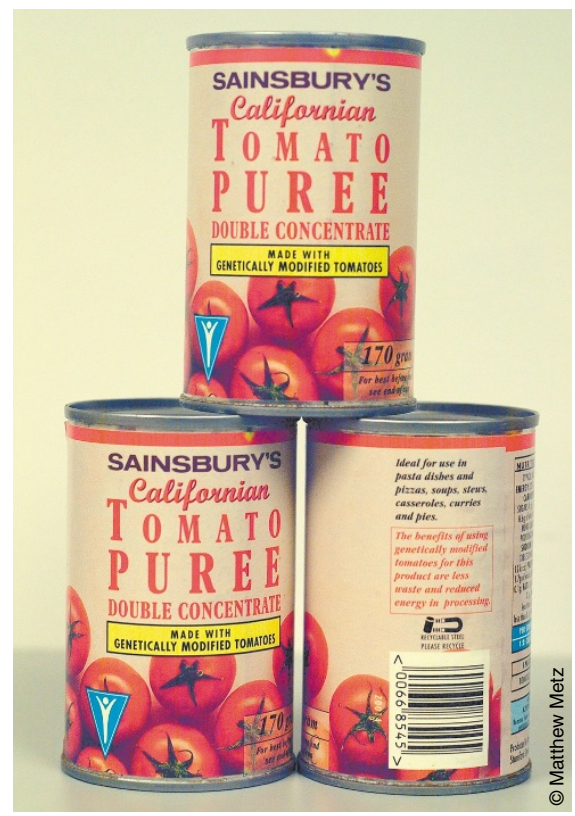

Does the public really want GM food labeled?

come to believe that I was mistaken to presume implicitly that choice requires mandatory labeling.

I now feel that in many circumstances it is better not to require such labeling but to permit retailers and restaurants that provide foods to decide, in a free-market environment, whether or not to label. In that way, the principle of choice holds both at the level of retailers and restaurants and at the level of individual consumers. If consumers really want to know whether or not the food they are buying or eating is from GMOs, they will seek out those retailers and restaurants that label. If, as I suspect is actually the case for most consumers, they haven't a deep interest in whether or not genetic modification has played a role, they won't seek out such labels. Exactly the same point holds with regard to the labeling of animal feed and consequent choices by farmers and others.
The issue can be examined more generally by asking why regulations (e.g., in regard to the labeling of food) are preferable to simply allowing people harmed by actions to take those responsible to court. One answer is that people want regulation to prevent such harms from happening. (I may be able to sue you for harming me because you have failed to show a duty of care by driving too fast, but I also may prefer that the harm had never happened, for example by my government having passed speeding-limit laws.) Another answer is that legal recourse is a very imperfect way to redress harms. Those with little money, power, or persistence stand only a small chance of successfully taking anyone, certainly a large company, to court.

These considerations suggest that the particular duties of a regulatory system are first, to prevent certain harms, and second, to protect those unable to take legal actions against those responsible for harms $s^{5}$. In the case of GM crops, I would therefore expect regulators to pay particular attention to those likely to be harmed and to those who lack agency. Some entities (such as farm animals and young children) potentially fall into both categories; other entities (such as adults with certain food allergies) fall into just one. It is precisely when it can be argued that considerable harm would (or might frequently enough) be prevented by labeling that there is a powerful argument for mandatory labeling. For this reason, I approve of mandatory labeling of foods that contain important allergens. (Importance here is defined by a combination of the severity of the allergy and the number of people with it.) Given the enormous amount of effort made in the United States, Europe, and several other regions to ensure that those GM foods that can be bought are at least as safe as conventional foods, I do not believe that it can validly be argued that mandatory labeling of GM foods is required.

\footnotetext{
1. European Parliament. Proposal for a Regulation of the European Parliament and of the Council Concerning Traceability and Labelling of Genetically Modified Organisms and Traceability of Food and Feed Products Produced from Genetically Modified Organisms (IP/01/1095, Brussels, July 25, 2001).

2. Dorey, E. Nat. Biotechnol. 19, 795 (2001).

3. Fox, J.L. Nat. Biotechnol. 19, 897 (2001).

4. Reiss, M.J. \& Straughan, R. Improving Nature? The Science and Ethics of Genetic Engineering (Cambridge Univ. Press, Cambridge, 1996).

5. Reiss, M.J. J. Agric. Environ. Ethics 14, 179-190 (2001).
} 